\title{
Red Blood Cell and Platelet Genotyping: from Current Practice to Future High-Throughput Donor Typing
}

\author{
Masja de Haas ${ }^{a} \quad$ C. Ellen van der Schoot ${ }^{\mathrm{a}} \quad$ Sigrid H.W. Beiboer ${ }^{\mathrm{a}} \quad$ Marianne Feskens $^{\mathrm{b}}$ \\ Goedele Cheroutre $^{\mathrm{a}}$ Petra A. Maaskant-van Wijk \\ a Sanquin Research and Landsteiner Laboratory, Academic Medical Center, University of Amsterdam, Amsterdam, \\ bSanquin Blood Bank South West Region, Rotterdam, The Netherlands
}

\section{Key Words}

Blood group genotyping

\section{Summary}

The molecular basis of almost all red cell and platelet blood group antigens is known. This enables the prediction of red cell or platelet phenotypes based upon the genotypes. In many laboratories, blood group genotyping assays are routinely used in cases where patient red cells cannot be used for serological typing due to the presence of autoantibodies (direct antiglobulin test (DAT)-positive) or after recent transfusion. Furthermore, fetal genotyping is routinely performed where there is a risk of alloimmune-mediated red cell or platelet destruction. In the Netherlands, medium-throughput human platelet antigen (HPA) genotyping has been introduced in the blood banks to guarantee direct (on-shelf) availability of HPA-1a- and HPA-5b-negative platelets for newborns suffering from neonatal alloimmune thrombocytopenia. The techniques used, pyrosequencing and TaqMan-based allele-specific hybridization assay, are discussed in this review. Recently, several research groups investigated whether red cell molecular typing could also be introduced for large-scale blood donor typing to obtain and maintain an inventory of typed (antigen-negative) donors. The reason for this is that phenotyping of large cohorts of donors is a labor-intensive exercise and hampered by the lack of sufficient amounts of approved typing reagents for all blood group systems of interest. Several approaches for high-throughput genotyping, based on DNA microarrays spotted on glass slides or beads, have now been tested and are also discussed in this review.

\section{Schlüsselwörter \\ Blutgruppengenotypisierung}

\section{Zusammenfassung}

Die molekularen Grundlagen nahezu aller Blutgruppenund Plättchenantigene sind bekannt. Dies ermöglicht die Vorhersage der Erythrozyten- und Plättchen-Phänotypen auf der Basis der Genotypen. In vielen Laboren wird die Blutgruppen-Genotypisierung eingesetzt, wenn die Erythrozyten von Patienten auf Grund von Autoantikörpern (positiver direkter Antiglobulintest, DAT) oder unmittelbar nach einer Transfusion nicht für eine serologische Typisierung verwendet werden können. Zudem werden auch bei Verdacht auf alloimmune Zerstörung der Erythrozyten oder Plättchen routinemäßig fetale Genotypisierungen durchgeführt. In den niederländischen Blutbanken wurde die Genotypisierung der humanen Plättchenantigene (HPA) im mittleren Durchsatz eingeführt, um eine direkte Verfügbarkeit (auf Abruf) von HPA-1aund HPA-5b-negativen Thrombozyten für Neugeborene mit neonataler Alloimmunthrombozytopenie zu gewährleisten. Die verwendeten Techniken, Pyrosequenzierung und TaqMan-basierter allelspezifischer HybridisierungsAssay, werden in diesem Übersichtsartikel diskutiert. Kürzlich haben mehrere Arbeitsgruppen untersucht, ob die molekulare Typisierung der Erythrozytenantigene zur Blutspendertypisierung in größerem Maßstab eingesetzt werden könnte, um einen Bestand an typisierten (Antigen-negativen) Spendern aufzubauen. Der Grund dafür ist, dass die Phänotypisierung größerer Spenderkollektive eine arbeitsintensive Aufgabe darstellt und durch fehlende Testreagenzien für alle Blutgruppensysteme erschwert wird. Mehrere Ansätze für die HochdurchsatzGenotypisierung basierend auf DNA-Mikroarrays, die auf Glasobjektträgern oder Beads aufgebracht sind, wurden getestet und werden in diesem Übersichtsartikel ebenfalls diskutiert. 


\section{Introduction}

In the Netherlands, part of the donor population is serologically typed for clinically relevant red cell blood group systems (Rhesus (Rh) CcDEe, K, Fy, Jk and MNSs). Furthermore, a number of platelet apheresis donors are genotyped for human platelet antigens (HPA) in order to have HPA-1a/5b-negative platelets available for neonates suffering from alloimmunemediated thrombocytopenia. HPA phenotyping is laborious, costly and, for most HPA systems, hampered by the limited availability of typing reagents. Hence, to obtain a typed donor cohort genotyping seemed to be the method of choice. Red cell phenotyping is performed with the very simple hemagglutination test which is done via an automated assay for the majority of red cell blood groups. However, complete phenotyping of all blood donors is too expensive, laborious and simply not feasible because of the lack of sufficient typing reagents (e.g. for high-frequency antigen typing). Therefore, if red cells of a very rare phenotype are needed, one has to resort to stored frozen products, e.g. in the Blood Bank of the Council of Europe.

For most blood group systems, the molecular basis is known and found to be a single nucleotide polymorphism (SNP). For updated information see: www.bioc.aecom.yu.edu/bgmut/ index.htm, www.uni-ulm.de/ wflegel/RH/, www.ebi.ac.uk/ipd/hpa/). Nowadays, in many laboratories, blood group genotyping assays are used for prenatal genotyping of fetuses at risk of hemolytic disease or in cases where patient red cells cannot be used for serological typing due to the presence of autoantibodies (direct antiglobulin test (DAT)-positive) or after a recent transfusion [1-3]. However, these assays cannot be used for high-throughput genotyping of numerous donors for a large panel of blood group systems. Recently, 4 papers were published on the possibility of DNA microarrays for highthroughput genotyping for red blood group antigens and platelet antigens. In this review, the current medium-throughput genotyping methods used for donor HPA typing in the Netherlands (TaqMan technology-based allele-specific hybridization assays and pyrosequencing) will be discussed. Furthermore, an overview of international developments in DNA microarray typing will be given.

\section{HPA Genotyping of Platelet Apheresis Donors}

HPA alloimunization may cause fetal and neonatal alloimmune thrombocytopenic purpura (FNAITP), posttransfusion purpura and platelet transfusion refractoriness [4-6]. FNAITP is caused by maternal IgG antibodies, which are directed against paternal antigens on fetal platelets, passing the placenta and causing fetal thrombocytopenia. Approximately $80 \%$ of FNAITP are caused by anti-HPA-1a antibodies and $10-15 \%$ by HPA-5b antibodies. Particularly in neonates with unexpected FNAITP, diagnostic tests and time to availability of matched platelet transfusions can cause an unacceptable prolongation of the period the newborns are at risk of bleeding. In the Netherlands, it was concluded that newborns would benefit from direct availability of HPA-matched platelet products. Similar to the UK, a large cohort of platelet apheresis donors was typed by molecular techniques to provide HPA1a/5b-negative platelets [7, 8]. Currently, typing is routinely performed by either pyrosequencing (South Western Region of the Netherlands) or TaqMan technology-based typing (North Western Region).

\section{Principle of Pyrosequencing}

A pyrosequencing reaction is based on the detection of realtime pyrophosphate that is released when a nucleotide is incorporated. First, a polymerase chain reaction (PCR) product is generated with 1 of the 2 biotinylated primers, which is then enzymatically treated and immobilized onto streptavidin-coated sepharose beads. After denaturation, a sequence primer is hybridized to the single-stranded template. All 4 enzymes needed for the pyrosequencing reaction are contained in the reaction mixture, and one by one, the deoxyribonucleoside triphosphates (dNTPs) are added automatically. When a nucleotide is incorporated, a light signal is generated by the luciferase reaction. The real-time light signals are presented in a pyrogram representing the sequence. Peak heights reflect the number of nucleotides that have been incorporated (fig. $1 \mathrm{~A}$, B). In the current design of pyrosequencing-based HPA genotyping, the HPA genotypes are determined individually. However, multiplexing of the PCR amplification and pyrosequencing reactions is possible, which increases the throughput and decreases the costs of the assay.

\section{Principle of TaqMan-Based Allele-Specific Probe Hybridization Assays}

TaqMan-based technology is an example of direct fluorescence-based detection of a PCR product in a 'closed' PCR, with the advantage that post-PCR handling is abolished $[2,3]$. For HPA genotyping, the assay is designed as a so-called endpoint fluorescence measurement. In this assay, gene-specific 'consensus' primers amplify a fragment of interest encompassing the HPA SNP. 2 probes, specific for either the A- or the-Ballele, are present during amplification. One of the probes is 5' end-labeled with a VIC-fluorochrome and the other with a FAM-reporter dye. Both are also labeled with a quenching dye which blocks the signal if the probe is intact. During amplification, the fluorescent dye at the 5' end of the probe is cleaved by exonuclease activity of Taq polymerase during primer extension. After PCR amplification, fluorescence is measured and automatically recalled and presented in a plot (fig. 2). 


\section{A}

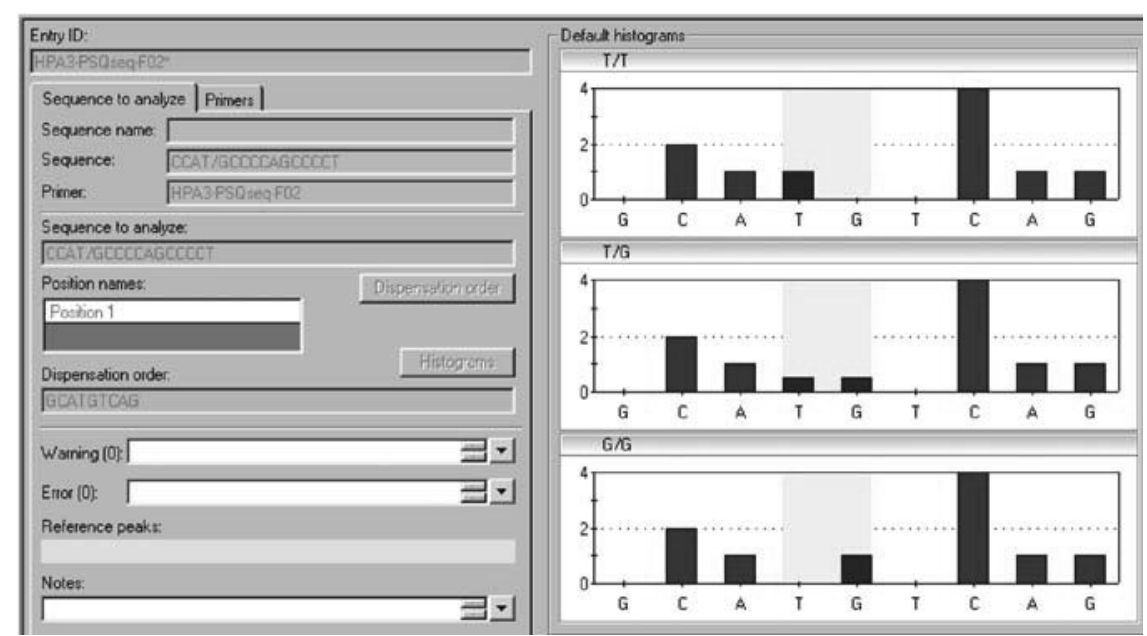

Fig. 1. Example of a pyrosequencing assay: HPA-3. The HPA-3 SNP is located in codon 843 of the GPIIb gene (Ile843Ser; T2621G). A The HPA-3 sequence to be analyzed is entered into the software. PSQ 96MA 2.1 Evaluation software advises a dispensation order of nucleotides and predicts the possible outcomes in histograms. B Pyrograms of HPA-3aa encoded by nt $\mathrm{T}$ (top), HPA-3ab encoded by nts $\mathrm{T} / \mathrm{G}$ (middle) and HPA-3bb encoded by nt G (bottom) in concordance with the histograms in figure $1 \mathrm{~A}$.
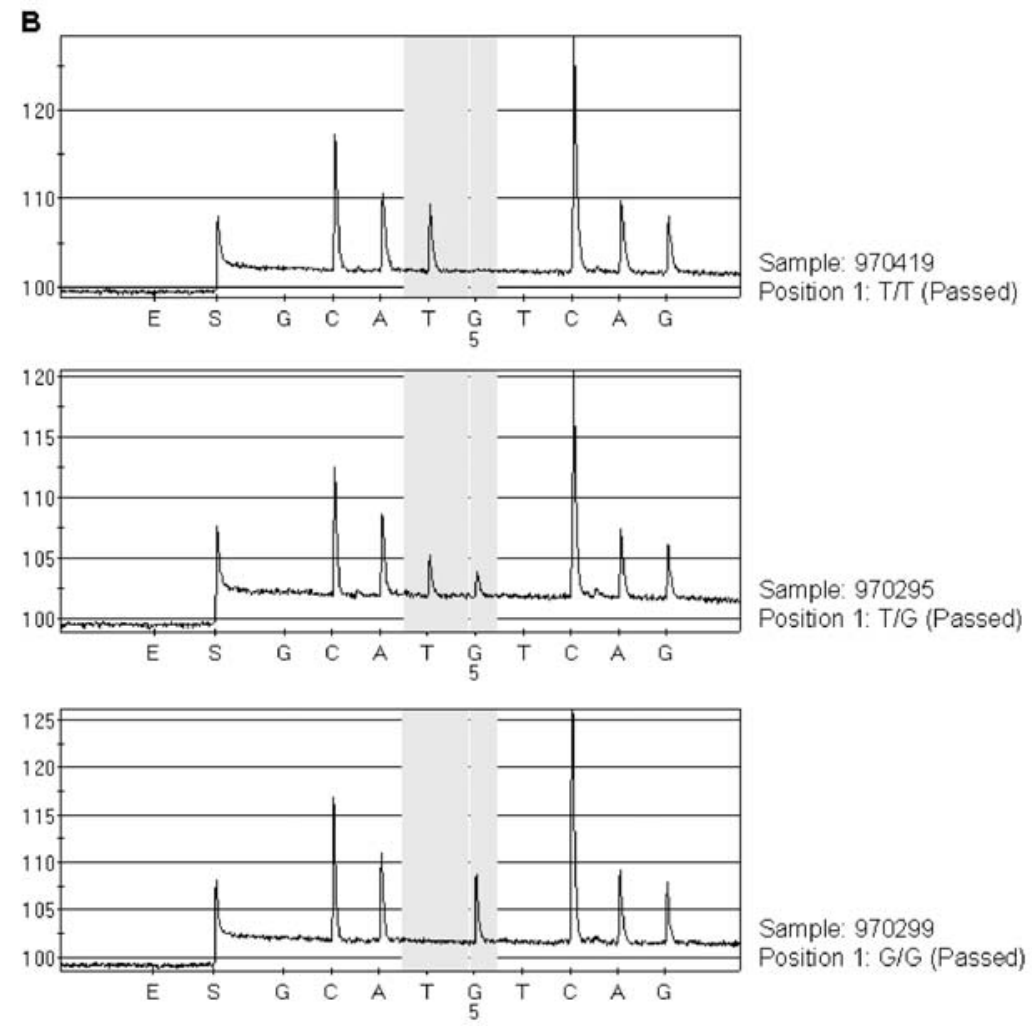

\section{HPA Genotyping in the Netherlands}

Only a limited number of donors is needed to provide sufficient numbers of HPA-1a/5b-negative platelet donors to guarantee direct (on-shelf) availability of typed platelets. Therefore, medium-throughput genotyping assays as described above can be used. Both methods can be easily automated and implemented in a fully automated setting in which DNA isolation robots (e.g. MagnaPure, Roche, Mannheim, Germany) are used for DNA isolation and DNA pipetting into the 96-well plate used for the HPA genotyping procedure. An electronic link between the bar- code of the blood sample and the test result of the ABIPRISM 7000/7700 (Applied Biosystems, Foster City, CA, USA) can be made to exclude pipetting or administrative errors. It has been estimated that the maintenance of a sufficiently sized HPA-1a/5b-negative donor pool requires additional typing of 1,000 donors per year. For this number of samples, pyrosequencing or TaqMan technology-based typing is more than sufficient. However, for the typing of a larger set of genotypes for a higher number of donors, DNA microarray-based typing appears to be a more cost-efficient platform. 


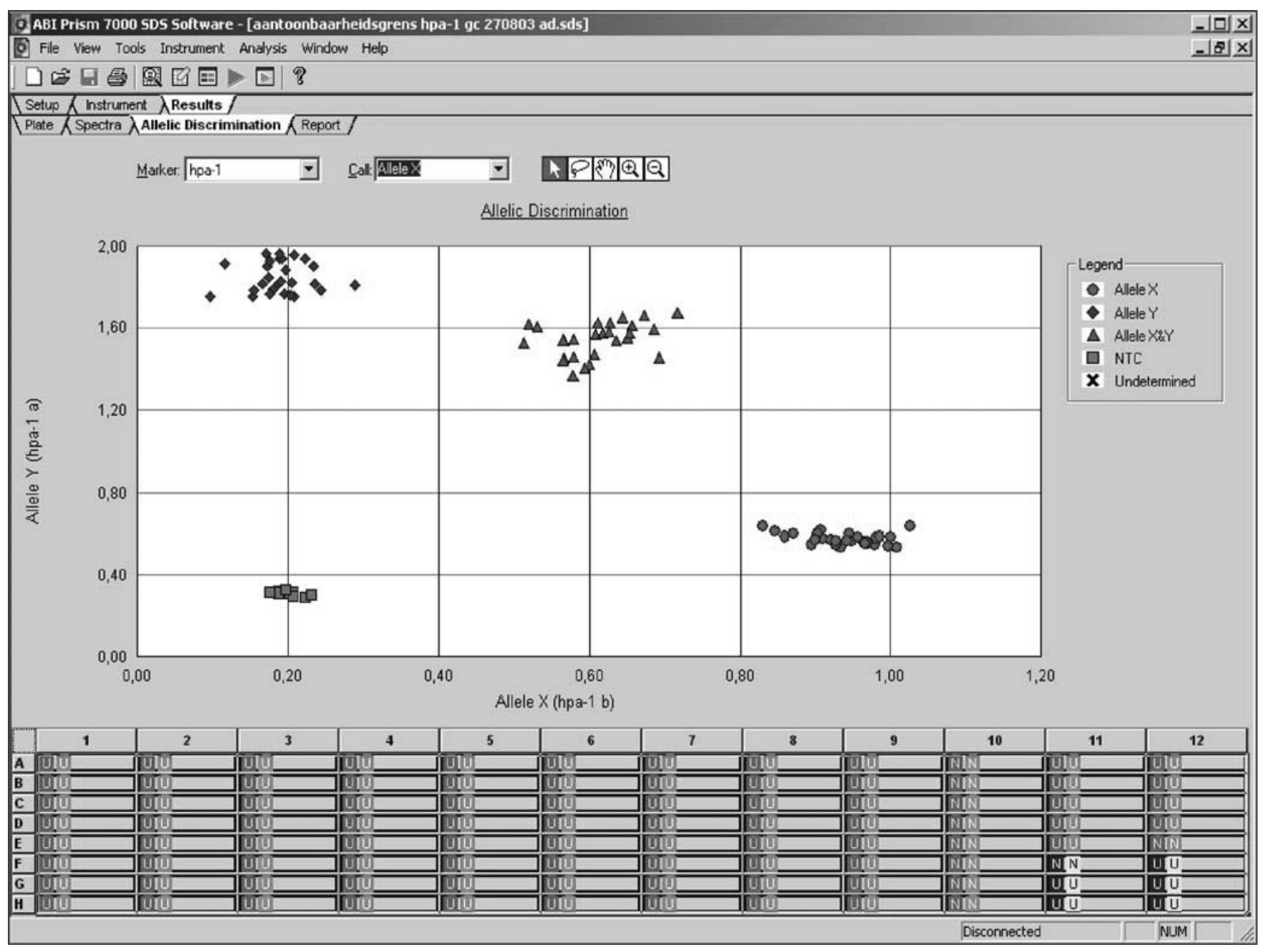

Fig. 2. Example of an automated HPA typing result for HPA-1 obtained with TaqMan-based alele-specific hybridization assays (Applied Biosystems).

\section{High-Throughput Genotyping of Blood Donors}

Last year, 4 papers presenting different methods for highthroughput red cell and platelet blood group genotyping were published in the same issue of Transfusion. Overall, 3 different types of genotyping methods were presented, which are illustrated in figure $3 \mathrm{~A}, \mathrm{~B}, \mathrm{C}$. Our group and Bugert et al. $[9,10]$ used a similar method of genotyping by allele-specific hybridization to allele-specific probes spotted onto glass slides (fig. 3A). In this method, first a multiplex PCR is performed which amplifies all fragments of interest. The obtained PCR product is labeled either during or after amplification and subsequently applied onto a glass slide which carries defined spots of oligonucleotides. These spotted oligonucleotides serve as probes specific for allele A or allele B, respectively. In most cases, the probes are 18-20-mers, carrying the allelespecific nucleotide in the central position. By changing the position of the SNP, probes that optimally discriminate between the 2 alleles can be selected. Per allele, a number of different probes is applied onto defined spots. After hybridization and washing, the quantity of bound fluorescent-labeled PCR product is measured with a microarray scanner. Subsequently, the genotype can be concluded by software, calculating signal ratios between the sets of spots specific for the A-allele and the B-allele (fig. 3A, fig. 4). We described a method in which a multiplex PCR was developed with gene-specific primers which all carry the same tags (fig. 5). These gene-specific primers are present in low amounts and will therefore amplify a gene fragment encompassing the SNP of interest only in the first PCR cycles. Universal primers which can bind to the tags are simultaneously present in excess and will determine final simultaneous amplification of all gene fragments. The use of universal primers facilitates a robust amplification of a large range of gene fragments. Currently, a multiplex PCR amplifying 30 different gene fragments ranging from 85 to $390 \mathrm{bp}$ in size is operational. In the method used by our group, the universal primers are labeled with a fluorochrome, and the final PCR product can be directly applied to the DNA arrays [9]. Also, in the method described by Bugert et al. [10], the oligonucleotides used in the multiplex PCR are carrying a $\mathrm{Cy}$ - 
A
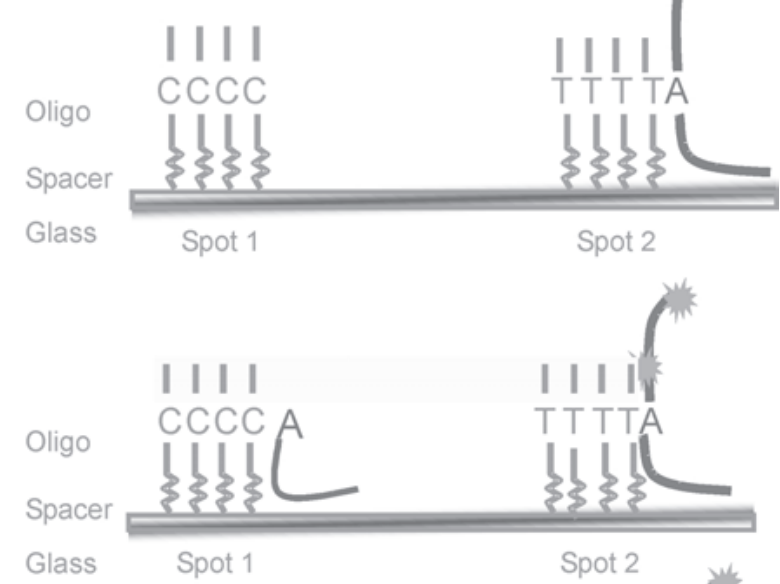

Glass

C

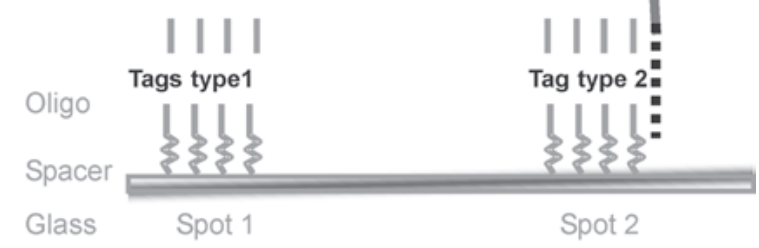

Fig. 3. 3 methods of genotyping by DNA microarrays. A Allele-specific hybridization to spotted oligonucleotides, B multi-base extension using allele-specific spotted oligonucleotides, and $\mathbf{C}$ single-base extension using gene-specific tagged primers that bind to complementary tag-specific spotted oligonucleotides.

3 label, and therefore the PCR product can be immediately analyzed by the DNA array. In the published papers, both Bugert et al. [10] and our group [9] focus on the typing for all clinically relevant HPA genotypes - HPA-1, $-2,-3,-5,-15-$ as a proof of principle of glass array-based genotyping by allelespecific probe hybridization. DNA microarray-based typing showed complete concordance with serological typing results or previously obtained typing results. For some assays, e.g. to facilitate typing of the GC-rich region of HPA-3, additional typing probes needed to be selected to optimize the assay.

Currently, our group have extended both the multiplex PCR and the DNA array with primers and probes, respectively, to type for a set of relevant red cell blood group systems. Furthermore, we are participating in a European consortium of scientists from the UK, Germany, Sweden, the Czech Republic and Spain, which aims to develop a robust red cell blood group genotyping DNA array (Bloodgen, www.bloodgen.com). Also, Bloodgen relies on genotyping by allele-specific hybridization to DNA arrays spotted on glass slides and is developing a method providing the typing of clinically relevant red blood cell blood group systems, including $\mathrm{ABO}$ and RHD, aiming to facilitate the typing of both donor and patient blood cells.

Hashmi et al. [11] describe a bead-based array (BeadChip, Illumina, San Diego, CA, USA). In this assay, a 14-pair multi- plex PCR amplifying gene-specific primers is used. The genotyping of the PCR fragments is performed by allele-specific oligonucleotide probes (20-21-mers), matching either allele A or allele B. The probes are covalently attached to color-encoded, spectrally distinguishable beads. In this assay, the singlestranded amplicons are added to the beads followed by an elongation reaction with a mixture of unlabeled dNTPs and TAMRA-labeled deoxycytosine analog (allele-specific multibase extension). Only in the case of a full match between the bead-coupled oligonucleotide and the PCR amplicon, elongation will proceed and the fluorescent label is incorporated (fig. 3B). An image of the fluorescence pattern of the beads which are presented as an array of approximately 4,000 randomly distributed beads is superimposed on a multispectral decoding image template to show the individual beads. Subsequently, comparable to glass-based arrays, the genotype can be deduced by determining fluorescent signal ratios between the 2 alleles. In a microplate format, the described platform supports the simultaneous typing of 96 DNA samples. All genotypes were in concordance with phenotyping or genotyping data. The challenge of this assay lies in obtaining sufficient high levels of specificity of the multi-base extension reaction by the allele-specific spotted oligonucleotides.

Finally, Denomme and van Oene [12] published a study with the GenomeLab SNPstream platform of Beckman Coulter, Fullerton, CA, USA. In this method, after a 12-pair multiplex PCR, the PCR-amplified fragments are treated with a cocktail of enzymes to degrade unincorporated PCR primers and deoxynucleotide triphosphatases. Subsequently, tagged extension primers are added, which are extended by single fluorochrome-labeled nucleotide terminator reactions (single base extension) and then spatially resolved by hybridization to the complementary oligonucleotides arrayed on a 384-well microplate (fig. 3C). In this design, the tag of the primer is specifically hybridized to probes that are spotted on the array. Measurement of bound fluorescent label and calculation of the ratios between signals derived from spots representing allele-A compared those representing allele-B provide the genotype. Individual sample results varied from 98 to $100 \%$ for 11 of the 12 SNPs. The limit of the described platform was 12 SNPs per microarray well, but the advantage is the high throughput in terms of number of donors that can be tested simultaneously. Denomme and van Oene [12] regard the platform as a useful tool to screen for clinically important blood group and platelet genotypes. Only identified antigen-negative donors need to be typed serologically, which optimizes the use of the limited available regulated typing reagents.

\section{Future Blood Donor Genotyping}

All authors of the above reviewed papers predict that red blood cell and platelet genotyping will be implemented in future donor typing. The escalating costs of commercial 


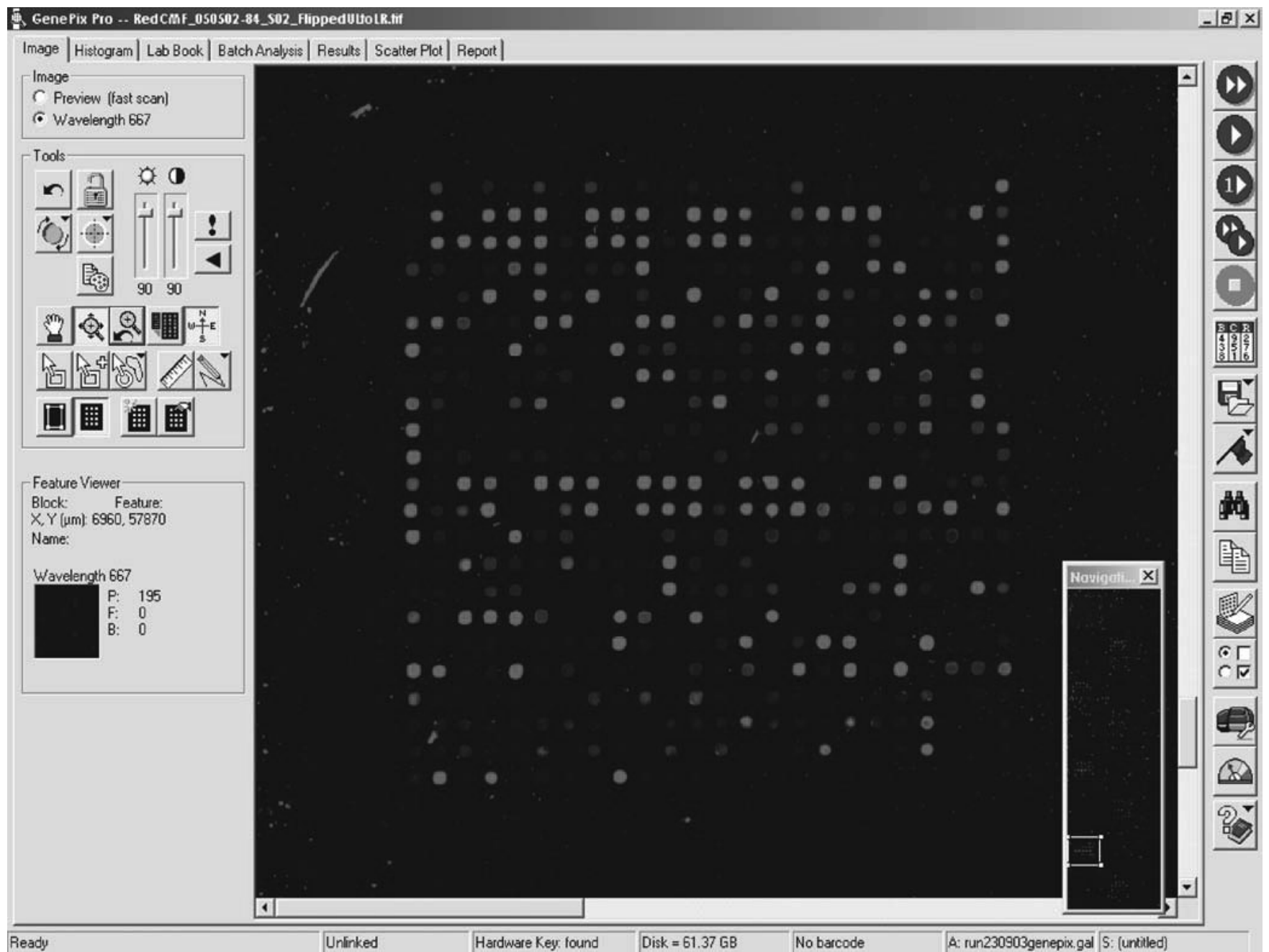

Fig. 4. Example of a microarray result after hybridization of fluorescent-labeled PCR products.

reagents, the lack of sufficient volumes of appropriate reagents and last but not least the labor-intensive hemagglutination testing and data entry (if not automated) make largescale full donor phenotyping costly. Cost-efficient genotyping platforms with a high throughput will be useful in this setting to increase the inventory of donors typed for clinically relevant blood groups needed in a daily transfusion setting (CcDEe, K, Fy, Jk, MNSs; antigen-negative blood). Furthermore, additional typing for high-frequency antigens and platelet antigens can be easily implemented. It should be noted that there will never be complete concordance between genotyping and phenotyping results. False-negative results (problematic in blood donor typing and in fetal blood group typing) can be due to mutations in the region of the blood group-defining SNP or in the regions to which the amplification primers anneal. False-positive results (problematic in the typing of blood recipients) can result from so-called silent or null alleles. Null alleles with a known frequency, such as the FYB allele carrying a GATA1 mutation or the RhD pseudogene, should be included in the setting of full patient or donor typing. An advantage of genotyping is the more reliable detec- tion of weak signals such as are generated by some of the weak-D phenotypes or the Fyx phenotype [13]. Furthermore, the availability of a fully typed donor cohort facilitates the matching of red blood cells to the recipient's blood type. Currently, in the Netherlands, typing and screening is the basis of the blood transfusion policy. ABO- and RhD-matched red cells are transfused, with the exception of girls and women $<45$ years of age who in general receive $\mathrm{ABO}, \mathrm{RhD}$-matched and K-negative red cells, and patients suffering from thalassemia or sickle cell disease who receive $\mathrm{Rh}$ phenotype compatible, K-negative blood. Further matching of blood group antigens between donor and blood recipient will prevent the occurrence of alloimmunization and potentially severe immediate or delayed hemolytic transfusion reactions [14, 15]. Prevention of red blood cell alloantibody formation will decrease the costs of pre-transfusion analysis for antibody identification and delays in donor blood selection. However, preventive matching for all clinically relevant blood group antigens in all blood recipients may introduce new problems in the direct availability of typed blood products because of a restricted inventory. Moreover, not all blood recipients do respond with 
Principle of multiplex PCR with a combination of tagged genespecific primers and fluorochrome-labeled universal primers

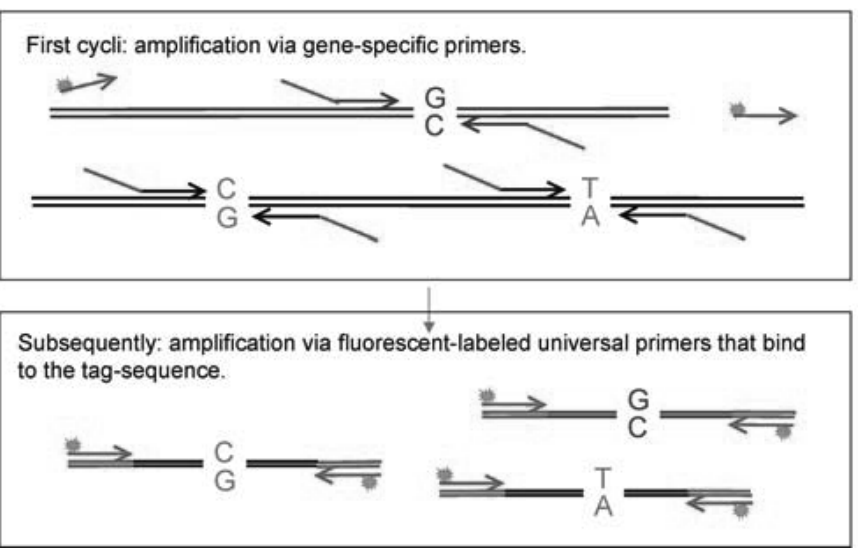

Fig. 5. Principle of multiplex PCR with tagged gene-specific primers and universal primers. alloantibody formation to a mismatched transfusion. Recently, additional data on links between HLA types and e.g. anti-D or anti-K formation have been published [16, 17]. It is expected that SNP genotyping will become part of the diagnostic workup to identify disease susceptibility, progression of disease, treatment response or risk of adverse reactions to certain drugs. As part of the work-up, blood group genotyping could be simply added, and, as Anstee [18] envisions, an electronic link between the hospital laboratory and the inventories in the hospital and blood center would allow automatic identification of the most compatible blood available. Whether this scenario will be implemented in the near future, mainly depends on the next step in the development of full donor typing and the complete automation of a cost-efficient high-throughput genotyping platform which will meet the high quality standards in the blood centers.

\section{References}

1 Reid ME: Application of DNA-based assays in blood group antigen and antibody identification. Transfusion 2003;43:1748-1757.

2 Van der Schoot CE: Molecular diagnostics in immunohematology. Vox Sang 2004;87(suppl 2):S189S192.

3 Yuan Yun Wu, Csako G: Rapid and/or highthroughput genotyping for human red blood cell, platelet and leukocyte antigens, and forensic applications. Clin Chim Acta 2006;363:165-176.

4 Warkentin TE, Smith JW: The alloimmune thrombocytopenic syndromes. Transfus Med Rev 1997;11: 296-307.

5 Davoren A, Curtis BR, Aster RH, McFarland JG: Human platelet antigen-specific alloantibodies implicated in 1162 cases of neonatal alloimmune thrombocytopenia. Transfusion 2004;44:1220-1225.

6 Kiefel V, Konig C, Kroll H, Santoso S: Platelet alloantibodies in transfused patients. Transfusion 2001;41:766-770.

7 Ranasinghe E, Walton JD, Hurd CM, Saul L, Smith G, Campbell K, Ouwehand WH: Provision of platelet support for fetuses and neonates affected by severe fetomaternal alloimmune thrombocytopenia. Br J Haematol 2001;113:40-42.
8 Allen DL, Samol J, Benjamin S, Verjee S, Tusold A, Murphy MF: Survey of the use and clinical effectiveness of HPA-1a/5b-negative platelet concentrates in proven or suspected platelet alloimmunization. Transfus Med 2004;14:409-417.

9 Beiboer SH, Wieringa-Jelsma T, Maaskant-Van Wijk PA, van der Schoot CE, van Zwieten R, Roos D, den Dunnen JT, de Haas M: Rapid genotyping of blood group antigens by multiplex polymerase chain reaction and DNA microarray hybridization. Transfusion 2005;45:667-679.

10 Bugert P, McBride S, Smith G, Dugrillon A, Kluter H, Ouwehand WH, Metcalfe P: Microarray-based genotyping for blood groups: comparison of gene array and 5'-nuclease assay techniques with human platelet antigen as a model. Transfusion 2005;45: 654-659.

11 Hashmi G, Shariff T, Seul M, Vissavajjhala P, Hue-Roye K, Charles-Pierre D, Lomas-Francis C, Chaudhuri A, Reid ME: A flexible array format for large-scale, rapid blood group DNA typing. Transfusion 2005;45:680-688.

12 Denomme GA, van Oene M: High-throughput multiplex single-nucleotide polymorphism analysis for red cell and platelet antigen genotypes. Transfusion 2005;45:660-666.
13 Garratty G: Do we need to be more concerned about weak D antigens? Transfusion 2005;45:15471551 .

14 Heddle NM, Soutar RL, O'Hoski PL, Singer J, McBride JA, Ali MA, Kelton JG: A prospective study to determine the frequency and clinical significance of alloimmunization post-transfusion. Br J Haematol 1995;91:1000-1005.

15 Redman M, Regan F, Contreras M: A prospective study of the incidence of red cell allo-immunisation following transfusion. Vox Sang 1996;71:216-220.

16 Chiaroni J, Dettori I, Ferrera V, Legrand D, Touinssi M, Mercier P, de Micco P, Reviron D: HLA-DRB1 polymorphism is associated with Kell immunisation. Br J Haematol 2006;132:374-378.

17 Hall AM, Cairns LS, Altmann DM, Barker RN, Urbaniak SJ: Immune responses and tolerance to the $\mathrm{RhD}$ blood group protein in HLA-transgenic mice. Blood 2005;105:2175-2179.

18 Anstee DJ: Goodbye to agglutination and all that? Transfusion 2005;45:652-653. 